\section{No conference critique}

Sir - As organizers of the fifth annual Euroconference on Apoptosis, held in Bingen/Rhine last autumn, we were surprised to read the article misrepresenting the quality and the costs of this Euroconference (Nature 392, 211; 1998). If the article was meant to be advertising for a forthcoming conference organized by young postdocs on research in apoptosis, it may have taken a wrong twist.

The Euroconferences on Apoptosis, organized by the European Cell Death Organization, are part of a series of meetings supported by the European Union. The size of the conferences is restricted to around 120 participants. The costs of last year's meeting were within the range of similar conferences (such as the Gordon Conference or Keystone Symposia). However, $50 \%$ of the noninvited participants, including $\mathrm{PhD}$ students and young postdocs, received funding from the European Union.

Participants were selected based on submitted abstracts. Additional support for the invited speakers came from Germany's research council, the Deutsche Forschungsgemeinschaft. The three-day meeting had 17 invited speakers and 18 oral presentations selected from submitted abstracts. Two poster sessions were held. All invited speakers and most of the selected speakers came from leading laboratories in the field and the data presented were mostly unpublished and/or conceptually important.

According to the questionnaire filled in by participants, the atmosphere at the meeting was congenial and the response enthusiastic. No critique related to the article in Nature was brought to the attention of the organizers. We feel that this clarification is important to ensure that the meeting series is not jeopardized. We do, however, appreciate and support the initiative of young postdocs to facilitate exchange at the planned First European Workshop on Cell Death.

Klaus-Michael Debatin

Peter H. Krammer

University Children's Hospital,

89070 Ulm, Germany

\section{Environmental costs of subsidies oversimplified}

Sir — Norman Myers, in his recent Commentary article, makes some cogent but somewhat simplistic observations about the economic and environmental costs that subsidies can inflict on society
(Nature 392, 327-328; 1998). I should like to add some comments.

First, a sharp distinction should be drawn between an explicit, marketdistorting public subsidy (for example, to Indian electricity users or Californian irrigators) and the many 'externalities' that characterize economic activity (agricultural pesticide runoff or urban congestion). In the former case, the marketplace provides clear-cut signals of the corrective action needed, however unpopular such action may be politically. In the latter case, although there has been significant progress in 'internalizing' externalities (for example through allowance trading under US limits on sulphur dioxide emissions), putting a monetary value on many externalities remains inexact and controversial.

Second, the dominant dilemma in fisheries is open access - a 'global commons' problem requiring cooperative approaches not amenable to being viewed in a subsidy framework.

Third, environmental improvement associated with removal of subsidies in one place may be diminished by developments elsewhere; German cutbacks in its highly protected coal industry may induce increased coal production in other countries and imports from abroad.

Finally, the beneficial subsidies of which Myers approves, such as those for renewable energy, may, on closer examination, be not so beneficial. The United States provides a handsome subsidy to corn processors producing ethanol, a costly policy whose consequences for an improved environment remain quite unclear. Joel Darmstadter

Resources for the Future, 1616 P St NW,

Washington DC 20036-1400, USA

e-mail:darmstad@rff.org

\section{Congressional hearings on genetics research}

Sir - You make the inference in your News item about the multicultural task force on genetics and ethnic minorities that the American Association for the Advancement of Science has an agreement with the group to organize legislative hearings (Nature 392, 428; 1998).

Following the involvement of the association in the two-day symposium sponsored by Howard University and Sinai Hospital, the organizers did contact my programme to learn about our experience in sponsoring non-partisan, legislative issue briefings in Congress.

Although we support the concerns of the task force and its desire to convene a briefing on this important topic, at no time was it discussed that the association would be one of the organizers.

Mark S. Frankel (Director)

Scientific Freedom, Responsibility and Law Program, American Association for the Advancement of Science, 1200 New York Avenue NW,

Washington, DC 20005, USA

e-mail:mfrankel@aaas.org

\section{An art form whose time has come}

Sir - Martin Kemp's series on Art and Science has been very welcome and I commend Nature for bringing this issue to the attention of readers.

A couple of Kemp's articles have focused on artists who have reached outside the studio and used nature as their artistic medium; I am thinking in particular of "Turrell's tunnelling"'. Perhaps the bestknown work of 'Earth-art' was created in 1970 by the American artist Robert Smithson (1938-73). I am referring to his monumental Spiral Jetty, a counterclockwise coil of rock and earth, 1,500 feet long and approximately 15 feet wide in the Great Salt Lake, Utah.

The spiral form is, of course, common in the natural world, such as mollusc shells; but, more importantly, the Spiral Jetty raises issues of time and scale, central theses in Smithson's work. As Smithson wrote, "each cubic salt crystal echoes the Spiral Jetty in terms of the crystal's molecular lattice. Growth in a crystal advances around a dislocation point, in the manner of a screw. The Spiral Jetty could be considered one layer within the spiralling crystal lattice, magnified trillions of times" ${ }^{\text {. }}$.

Smithson, like his contemporary Donald Judd (1928-94), had a strong interest in geology and especially the nature of geologic time.

The Spiral Jetty, now submerged, continues to evolve as it is eroded, until nothing will remain. As an ephemeral work of art it confronts time, and forces us to think about the duration, not only of art, but also of geological processes and the shaping of the geologic past.

Smithson sought an art form that could encapsulate the furthest reaches of time and space; a purist notion, indeed, but one most worthy.

\section{John Dalton}

Department of Geosciences,

University of Texas at Dallas,

Richardson, Texas 75083, USA

e-mail:dalton@utdallas.edu

1. Kemp, M. Nature 391, 131 (1998).
2. Smithson, R. in Robert Smithson: The collected writings(ed. Flam, J.) 143
(Univ. California Press, Berkeley, 1996). 